\title{
Estado e ações coletivas na África do Sul e no Brasil: por uma sociologia contemporânea dos países não exemplares ${ }^{1}$
}

MARCEO ROSA*

\section{Resumo}

O artigo busca, por meio da análise da atuação do Movimento dos TrabaIhadores Rurais Sem Terra (no Brasil) e do Landless People's Movement (na África do Sul), analisar as formas emergentes que o Estado adquire nesses dois contextos sociais. 0 objetivo central é mostrar que nesses países, chamados aqui de não exemplares, é preciso que se desenvolva uma teoria complexa que rompa com o dualismo sociológico Estado/Sociedade civil. Romper com os esquemas analíticos tradicionais, voltados para o caso europeu, significa necessariamente ter que triIhar novos, e menos preconceituosos, caminhos para compreender as formas políticas de pertencimento social nos países do sul.

Palavras-chave: Ações coletivas. Estado. Reforma agrária. África do Sul. MST

\footnotetext{
* Professor do Departamento de Sociologia e do Programa de Pós-Graduação em Sociologia e Direito/UFF

marcelocr@uol.com.br

1 A pesquisa que deu origem a este texto foi financiada, em parte, pelo Edital IBSA - Fundação Ford/ IUPERJ. $O$ trabalho de campo na parte africana foi realizado em conjunto com Antonádia Borgesa quem devo também o acesso a boa parte da bibliografia que utilizo aqui.
} 


\section{Introdução}

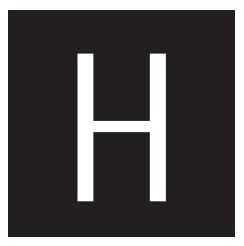

á vários caminhos para se abordar o tema da relação Estado/Sociedade Civil, desde os debatesteóricos até aqueles que visam descrever situações concretas e singulares. Neste texto, 0 interesse é relacionar estes tipos de construções por meio do itinerário epistemológico (Sayad, 1998:15) desenvolvido a partir de duas pesquisas realizadas no Brasil e na África do Sul respectivamente com militantes do M ST (M ovimento dos Trabalhadores Rurais Sem-Terra) e de movimentos dissidentes no estado de Pernambuco e com ativistas do LPM (Landless People's Movement) na província de Kwazulu-N atal ${ }^{2}$. Ao abordar o caso de ações coletivas rurais nesses dois países, estarei enfrentando aqui dois fantasmas i) o primeiro, de que nem Brasil, nem África do Sul seriam bons exemplos para uma teoria sociológica que envolva Estado e ações coletivas (seríamos até mesmo subcidadãos, para alguns ${ }^{3}$ ); e ii) de que as áreas rurais também não seriam boas para pensar nessas categorias em termos modernos.

Como a própria idéia de itinerário epistemológico sugere, a aproximação entre esses dois casos se origina da íntima relação que esses movimentos têm desenvolvido desde o início da década por meio de visitas mútuas periódicas. Desde sua fundação em 2001, o LPM se inspira nas ações e símbolos de seu correspondente brasileiro, inclusive vestindo as camisetas e tremulando as bandeiras do MST em suas manifestações públicas.

0 ponto de convergência entre os dois casos não teve origem apenas na relação entre os movimentos, mas também na oportunidade que tive de

\footnotetext{
2 A pesquisa no Brasil vem sendo realizada, em diferentes etapas, desde 2001. 0 caso sul-africano começou a ser trabalhado no ano de 2005.

3 Veja-se, por exemplo, Souza (2003).

40 MST, no ano de 2005, confeccionou no Brasil e enviou para a África do Sul camisetas vermelhas com os slogans e símbolos do LPM.
} 
acompanhar a viagem de militantes do M ST para África do Sul e de ter sido assim introduzido no LPM por meio do movimento brasileiro 5 . Ao longo das próximas páginas, procurarei demonstrar como o envolvimento na pesquisa comparada permitiu expandir os significados da investigação que comecei a desenvolver na época. Da mesma forma, apontarei para o fato de que a comparação me permitiu repensar os resultados de investimentos de pesquisa que haviam sido feitos sobre o próprio M ST, principalmente nas implicações teóricas que as ações desse movimento despertam.

\section{Sobre os desvios obrigatórios da pesquisa}

Partirei aqui de uma pesquisa realizada com movimentos dissidentes do MST em Pernambuco, para chegar ao caso do LPM . N os dois contextos de pesquisa, o objeto inicial poderia ser limitado pela categoria analítica movimento de sem-terras e nas suas formas internas de articulação entre ação coletiva e experiência biográfica de seus membros. Não havia, portanto, o interesse prévio pelo tema do Estado, que agora se mostra tão importante. No entanto, o que se observou em ambos os casos é que a compreensão de tal articulação passava irremediavelmente pelas formas como tais, ações, ao mesmo tempo, coletivas e individuais se pautavam por processos sociais organizados e/ou orientados para políticas de Estado. Nas próximas páginas procurarei, por meio desse itinerário, ou seja, pelo próprio caminho que a pesquisa seguiu ao longo dosúltimosanos, discorrer sobre a centralidade heurística das relações com o Estado para uma teoria social contemporânea nos países não exemplares.

5 Essa viagem ocorreu em julho de 2005 e os militantes brasileiros ficaram na África do Sul por três meses. Depois disso, tornei a encontrar os ativistas do LPM em março de 2006 no Brasil, entre julho e setembro de 2006 e entre Janeiro e março de 2007 na África do Sul. 


\section{O MST, seu modelo e seus equivalentes dissidentes}

São inúmeras as facetas das ações que o MST promove em todo o território brasileiro, tais como marchas, acampamentos, ocupações de latifúndios e de prédios públicos. Tendo em vista que esse movimento já existe há mais de 20 anos e de que esse rol de ações, iniciadas entre os pequenos produtores da região sul, cobre praticamente todos os estado do País, creio que podemos tomá-lo como um exemplo significativo das ações coletivas contemporâneas. A priori, essas diversas formas de ação coletiva em seu conjunto apontam para um mesmo sentido: a desapropriação de terras improdutivas, por parte do Estado, para o assentamento de trabalhadores. Esse argumento já seria suficiente para demonstrar a íntima relação entre esse movimento social e o poder estatal no Brasil. Nesse sentido, poderíamos supor que o movimento luta para fazer aquilo que o Estado não quer fazer, ou ainda, que luta contra o próprio Estado e suas formas tradicionais de ação.

Sinceramente não me parece que a Sociologia tenha avançado muito, seguindo os caminhos acima apontados. Se, em certos casos, encontramos em meio aos discursos dos movimentos, uma retórica antiestatal, isso não significa necessariamente que esse leimotiv seja aquilo que move os movimentos ${ }^{6}$. Desviar desse caminho não significa, porém, apostar de imediato na via contrária que se sustenta no jargão sociológico pela palavra cooptação (dos movimentos pelo aparelho do Estado). A ressalva aqui se faz necessária porque qualquer um desses pólos parte das mesmas premissas: de que a Sociologia pode conhecer o sentido "verdadeiro" da ação e de que as relações sociais se sustentariam apenas numa disputa de poder diádica (do tipo sociedade/Estado). Por ora, para não esquecer que este debate somente

6 A implicação desse tipo de recurso anti-estatal para a organização dos movimentos sociais, apesar de importante, não será objeto desse texto. Autores como M artins (2000) e N avarro (2002) chamaram atenção para esse problema sem, no entanto, aprofundarem-se nas implicações sociológicas do fenômeno. 
foi possível depois de vários anos de pesquisa sobre o tema, retomarei o caso que primeiro me inspirou.

O MST chegou à região canavieira de Pernambuco em 1989, por meio de militantes que migraram de outros estados do País a fim de mobilizar trabalhadores rurais das lavouras de cana-de-açúcar para que exigissem do Estado a desapropriação de terras improdutivas - em sua grande parte ocupadas nas décadas passadas por engenhose usinas. Como apontei anteriormente (Rosa,2004), o movimento enfrentou enormes dificuldades para se estabelecer naquela área, sobretudo porque inicialmente não conseguiu diálogo nem com os sindicatos de trabalhadores rurais (que monopolizavam a representação política daqueles trabalhadores) nem com os próprios agentes do Estado (habituados de igual forma às interpelações de trabalhadores da cana) ${ }^{7}$.

Essa situação começou a se alterar no ano de 1992 quando - por meio de contatos pessoais entre um dirigente sindical e alguns jovens militantes do MST (formados na própria região, isto é, não mais outsiders) - os dois grupos realizaram uma ocupação conjunta de uma fazenda. A ocupação foi intensamente reprimida pelo aparelho de segurança do Governo do Estado, que optou por garantir o direito daqueles que se diziam proprietários da área (onde nada se produzia na terra, mas na qual funcionava uma grande usina de produção de açúcar e álcool). A repressão teve como efeito a intensificação da mobilização dos sindicalistas e militantes e o aumento dos interesses de pessoas da região em participar de um acampamento. Segundo Sigaud (2000), a ocupação de 1992 desencadeou, nos meses seguintes, uma saga de outras ocupações que não foram reprimidas com a mesma força e que chamaram a atenção dos agentes do Estado para a possibilidade de desapropriarem fazendas improdutivas na região. As ocupações foram capazes de introduzir no vocabulário local a expressão sem-terra, uma cate-

7 Ver Sigaud (1979) e Palmeira.(1978). 
goria que até então era secundária em relação a outras como desempregados ou clandestinos ${ }^{8}$, próprias ao universo marcado pela relação entre trabaIhadores e senhores de engenho. Até aquele momento, os esforços do Estado na região procuravam garantir os direitos trabalhistase, quando isso era impossível, a sobrevivência dos trabalhadores na época da entressafra; a partir dali se abriu uma nova frente para a presença estatal: atuar em acampamentos e assentamentos de reforma agrária.

Como trabalhei em Rosa (2004b), as ocupações que foram iniciadas pelo MST em conjunto com os sindicatos de trabalhadores rurais passaram, ao longo dos anos, a suscitar a participação de outros grupos, os quais, por sua vez, capitanearam um processo de disputa em torno desse objeto aparentemente comum a todos que eram as ocupações. Em 2002 existiam, apenas no estado de Pernambuco, 14 movimentos que realizaram ocupações de terra e de prédios públicos. Todos esses movimentos copiavam aquilo que chamei de forma movimento, ou seja, repetiam com pequenas mudanças a estrutura das ações do MST (todos formaram um acampamento em uma terra improdutiva e, logo a seguir, ocuparam a sede do instituto Nacional de Colonização e Reforma Agrária) e também de seus símbolos (cada um delespossuía uma bandeira própria, maioria dos casos reformulando as figuras adotadas pelo $\mathrm{MST})^{9}$.

Ao longo da pesquisa, descobri que todos os movimentos haviam sido formados por pessoas que, em determinado momento de suas vidas, tinham mantido relações próximas ou mesmo tomado parte no MST. Foi por meio dessas dissidências e das formas pelas quais elas justificavam suas saídas é que se abriram os caminhos para pensar a relação entre Estado e ação coletiva.

8 Clandestino era o trabalhador que vendia sua força de trabalho, sem que o patrão reconhecesse formalmente (diante do Estado) o vínculo trabalhista. Sobre um estudo pormenorizado da categoria ver Sigaud (1979).

9 Nesta pesquisa foram entrevistados lideres dos seguintes movimentos: MTRUB, MTBST, O LC, MLST, MTL, CPT, FETAPE, MTB e MST. 


\section{O s movimentos dissidentes}

Nesta seção, abordarei o caso de dois desses movimentos. Em ambos, as lideranças foram militantes do MST por um período e, a seguir, acabaram por criar movimentos próprios. O MTRUB (M ovimento dos Trabalhadores Rurais e U rbanos do Brasil) e o M TBST (M ovimento dos TrabaIhadores Brasileiros Sem Terras) foram criados na pequena cidade de Amaraji, região canavieira de Pernambuco, entre 2000 e 2003. O s dois movimentos são considerados pequenos em relação ao MST, e seus quadros de dirigentes se resumem à família e aos amigos dos então militantes. Sua força e legitimidade residem no fato de que ambos, quando deixaram o MST, eram líderes de acampamentos com algumas centenas de pessoas que apoiaram sua decisão de rompimento.

No caso desses movimentos dissidentes, os motivos arrolados durante a pesquisa, que justificavam os descontentamentos de seus líderes, para fundarem seus próprios grupos, residiam na incapacidade que o MST teve de atender as demandas das famílias acampadas ${ }^{10}$.

A forte hierarquização das funções no interior do movimento certamente contribuía para o surgimento desse tipo de descontentamento ${ }^{11}$. Nos casos que acompanhei, para ter a atenção do movimento (ou seja, para que o acampamento e os acampadosfossem colocados como prioridade nas demandas do MST ao Estado) era preciso que a liderança do acampamento tivesse boas relações com a coordenação estadual e, principalmente, uma dedicação exclusiva ao movimento ${ }^{12}$. Essa relação não se encerrava apenas

10 Acampamento é o ato de ocupar uma terra privada e nela montar barracas para exigir do Governo Federal a desapropriação da área. Assentamento é a terra desapropriada que é distribuída aos acampados, mediante um contrato de pagamento de longo prazo.

11 A hierarquia do MST é composta por coordenações de tarefas (vigilância, saúde e educação entre outros), de acampamentos, de microrregiões, de regiões, de estados e da coordenação nacional. Em geral, são os coordenadores de regiões e de estados que deliberam sobre as açõese prioridades do movimento.

12 Gostaria de lembrar aqui o caso de um militante entrevistado durante a pesquisa que entrou e saiu do MST várias vezes. Sua admiração e gratidão pelo movimento eram expressados por meio de 
no empenho individual e dependia da situação jurídica da área a ser desapropriada, do número de pessoas no acampamento e na capacidade do coordenador local em seguir as regras internas do movimento.

É preciso saber que a liderança do acampamento foi, em geral, a pessoa que mobilizou as famílias acampadas. Foi ela que as seduziu a entrar naquela aventura. Isso a torna também a principal e, por vezes, a única relação entre as pessoas que ali estão e o movimento.

Segundo o que foi possível perceber em entrevistas e reuniões públicas e privadas das quais participei com esses sujeitos, ocupar um lugar importante na hierarquia do MST significava, para lideranças locais, aumentar as possibilidades de retribuírem a confiança neles depositadas no momento no qual seus amigos, vizinhos e parentes decidiram engajar-se em um acampamento. Retribuir essa confiança significava, no caso estudado, garantir a desapropriação da terra desejada. Porém, entre o dia da ocupação da terra e, nos casos bem-sucedidos, o recebimento da posse, costumavam passar-se vários anos. Durante este tempo, a vida no acampamento depende basicamente de cestas de alimentação, que são distribuídas pelas Prefeituras ou pelos Governos Federais, estaduais e municipais. Além da subsistência, para que o processo se efetive é imprescindível que o acampamento se mantenha em pé e protegido dos ataques das milícias privadas, financiadas pelos proprietários da terra. É necessário também que a área seja vistoriada e que se garanta a celeridade de um correto andamento jurídico e burocrático dos processos de desapropriação ${ }^{13}$. Este conjunto de tarefasé creditado, pelasfamílias acampadas, ao coordenador do acampamento, em

seus relatos de viagens pelo País e pelos cursos e escolas que freqüentou. Ele chegou a ser, por um curto período, coordenador de uma das regionais do movimento. No entanto, como tinha mulhere filhos que dependiam dele, e como as ajudas financeiras que o movimento dá a seus militantes não são regulares, ele não pôde seguir sua vida apenas como um militante.

13 Nos casos que estudei, o MST mantinha uma lista de prioridades que eram apresentadas aos representantes do Estado. As prioridades se davam, tanto em relação ao tipo de demanda, como cestas básicas, por exemplo, como em relação a qual acampamento deveria receber primeiro. 
geral, uma pessoa de confiança de todos. Se o processo não anda, se as cestas básicas não chegam, as pessoas passam a perder a confiança no acampamento e, por extensão, na sua liderança.

$\mathrm{N}$ ão por acaso, a maioria dos movimentos dissidentes havia sido formada por líderes de acampamentos que fracassaram no atendimento das expectativas das pessoas acampadas sob a bandeira do MST.

$\mathrm{N}$ as diversas oportunidades que tive de entrevistar e conversar com essas lideranças, emergia sempre a idéia de que a situação de acampamento se tinha tornado injustificável, pela demora ou pelo simples abandono diante de casos considerados mais importantes pelo movimento. Se esse sentimento se espraiava entre as pessoas acampadas, para os coordenadores do acampamento ela parecia ser mais grave. Eles se sentiam desrespeitados pelo movimento (assim como os demais) e também pelas pessoas que tomavam parte nos acampamentos e que não os reconheciam mais como líderes ao abandonarem as barracas do acampamento. Vemos assim, que o desempenho individual dos coordenadores depende da ação do M ovimento e que a imagem do movimento, diante dos acampados, depende também do empenho dessas pessoas.

Como afirma Boltanski (2000: 92), toda disputa envolve a associação entre pessoas e coisas que são os símbolos ou as provas que permitem a própria disputa, no sentido de uma relação social. Somente podem entrar nas disputas por terra pessoas que se unem por um período de tempo indefinido e que se identificam com um objeto que julgam merecer. A questão que este texto enfrenta é justamente compreender quais foram os objetos que reuniram aquelas pessoas, naquele momento e que permitiram sua relação social na forma de um movimento de sem-terras.

Desde o ponto de vista dessas pesquisas, centrar todas as repostas no desejo pela terra não é suficiente, Pelas pistas que temos, há outros objetos compondo um conjunto que nos livra da armadilha monocausal de trabaIhar apenas com relação aos fins da ação coletiva Acreditar que as pessoas 
que se engajam, das mais diferentes formas, em um movimento de semterras o fazem apenas porque desejam terra é esquecer que, apesar de sempre ter havido gente querendo terras, foram poucas as vezes na H istória, que elas apareceram organizadas dessa forma.

Ao longo da pesquisa, alguns objetos foram continuamente disputados, servindo de amálgama por um tempo e, a seguir, de prova para os rompimentos que observei nos casos de Pernambuco. Em momento algum, ouvi pessoas dizendo que haviam desistido de acampar porque a terra já não Ihes interessava (temos que levar em conta que os interesses pela terra são os mais diversos), elas diziam, na maior parte dos casos, que o problema estava no movimento. Não especificamente no MST como organização, mas na situação em que se encontravam em um momento específico.

$O$ fato de as pessoas como os líderes do MTRUB e MTBST terem abandonado o M ST, masnão a idéia de movimento sinaliza um ponto fundamental: nas disputas contemporâneas por terra, as pessoas estão obrigatoriamente ligadas ao objeto movimento.

Essa ligação por meio do movimento não é, no entanto, perene e somente se construiu sob certas circunstâncias históricas. Seguindo os caminhos trilhados por Boltanski, (2000) e Boltanski e Thévenot (1991), a dignidade que lhes permite agir legitimamente está relacionada à forma como cada sujeito justifica suas ações (como constrói sua grandeur diante dos demais), ajustando situacionalmente o objeto da disputa (prova) e à ação social ${ }^{14}$. N esse caso, entre as lideranças, os movimentos e a situação histórica do acampamento. Esse esquema nos permite pensar nas seguintes questões: por que as pessoas consideravam importante se relacionarem com outras, por meio de um movimento? Como elas compreendiam a

14 Apesar da inspiração nos escritos de Boltanki (op. cit) e de Thévenot (2006), não acredito que a grandeur possa estar limitada a um número específico de formas situacionais que compõem a sociedade moderna como nos caso das "cidades" apresentadas por estes. 
posição social que o movimento Ihes trazia nos momentos de unidade e de ruptura?

Firme na tentativa de não tomar as explicações naturalistas para compreender a relação daqueles indivíduos com os movimentos, deixei em suspenso os efeitos organizacionais que o MST poderia exercer sobre aqueles homens e mulheres ${ }^{15}$. Nesse caso, me interessei particularmente pela construção discursiva elaborada pelos dissidentes para justificar seu rompimento com o MST e, ao mesmo tempo, sua continuidade na seara dos movimentos de luta por terra. 0 ponto que ali se colocava era compreender a economie $d u$ grandeur que compreendia a formação daqueles pequenos movimentos que, por vezes, eram mais conhecidos por serem o "movimento de fulano" do que por seu nome oficial. Enfim, compreender essas formas de engrandecimento social que permitiam aquela relação cujo ícone era o movimento.

Como afirmei acima, nos casos dos movimentos que foram formados por antigos militantes do MST (na época o MTRUB e o MTBST), havia uma recorrência ao fato que aquele movimento havia abandonado (no sentido de não dar atenção) o acampamento do qual esses homens eram coordenadores. 0 abandono era a situação (reflexivamente construída) que permitia que ambos, legitimamente, se desvinculassem do MST e, ao mesmo tempo, os credenciava a se apresentarem como autônomos em outros espaços sociais. 0 movimento como objeto de disputa, por sua vez, era a prova (o objeto) que Ihes permitia continuar representando aquelas famílias diante do Estado (sua grandeur).

Notamos então que, nesta situação, o movimento deixa de ser sinônimo do MST e se expande para uma forma legítima e geral capaz de ser situada e reconhecida pelos agentes que então se ajustam em relação a ela. O u seja, naquela situação específica, as pessoas se tornaram capazes de 
compreender, avaliar e mensurar a relação entre o MST e a forma movimento que já não era necessária como em outros momentos ${ }^{16}$.

\section{Movimentos e Estado: forças pluridimensionais}

Como também esclareci acima, o movimento como forma não envolve apenas a organização e os acampados. Ele somente se mantém legítimo (ou seja, capaz de colocar seus líderes, membros e acampados numa condição de se apresentarem publicamente como parte de uma mesma comunidade moral), na medida em que consegue mobilizar as estruturas do Estado (seja para a desapropriação da terra ou para a distribuição de cestas básicas). Ao menos, foi assim que esses líderes descreveram seu processo de cisão, e foi isso que vi quando eles se encontravam diretamente com o superintendente do INCRA em Recife. Somente depois de terem fundado seu próprio movimento é que eles foram recebidos pessoalmente pelo representante do Governo. Nesse momento, puderam engrandecer-se individualmente (ao mobiliar o objeto ad equado para a ocasião) e se tornarem aptos à socialização, em um espaço que antes lhes era interdito como homens comuns.

A pressão sob essas lideranças para que criassem novos movimentos não vinha apenas dos acampados (que se sentiam desamparados). Eles foram também estimulados pelo superintendente do IN CRA em Pernambuco que lhes garantia que, se formassem seu próprio movimento, deixando 0 MST, seria mais fácil encaminhar as demandas locais. Não me parece que isso seja uma tática do Estado para dividir os demandantes e/ou para minar seu poder de mobilização. Também não definiria o que presenciei como uma estratégia para "facilitar a administração central da produção e do controle da vida pública" (Scott, 1998: 348), como se o Estado fosse, por de-

16 A idéia de forma movimento surgiu, ainda de modo provisório, em Rosa (2004a), inspirada em Sigaud (2000), foi desenvolvida em Rosa (2006) e aparece aqui em uma versão retrabalhada. 
finição, um ente dotado de um desejo aprisionador. Isso poderia até ser considerado se o efeito não tivesse sido o contrário: quanto mais movimentos eram formados, mais ocupações aconteciam e mais demandas eram feitas (e, ainda assim, a formação de movimentos era incentivada). No tempo em que estive por lá, as ocupações do prédio do Incra eram tão rotineiras, que se aventava nos jornais, a possibilidade de transferir a sede do órgão para fora da cidade a fim de evitar os freqüentes transtornos ao trânsito, causad os pelas barracas que ocupavam as calçadas.

Mesmo que na época da pesquisa estivéssemos no governo $F . H$. Cardoso (que havia criminalizado, por meio de medida provisória, as ocupações de terra e de prédios públicos), e o superintendente fosse por ele nomeado, via-se claramente um reforço da forma movimento de reivindicar.

Assim, o primeiro obstáculo a ser enfrentado é o de que, assim como o MST não controlava sua própria forma, o Estado, ao ser visto como um governo de formas complexas e não como um estamento (Li, 2005 e Borges, 2005), não atinge a todos os seus agentes da mesma maneira.

Ao longo dos três anos que estive em Pernambuco, chamava atenção o comportamento dos funcionários do INCRA em relação aos movimentos e suas ações. H avia um grupo minoritário que resistia em aceitar o repertório de ações instituído pelos sem-terras, em geral valendo-se do mesmo argumento que se poderia encontrar nos jornais (seriam aproveitadores, baderneiros e privilegiados). Porém, o que acompanhei na maioria dos casos foi o empenho, sob circunstâncias de escassos recursos materiais, dos funcionários em atender e encaminhar as demandas que eram feitas diariamente ao Instituto. M esmo quando não estava ocupado formalmente por um movimento, as ante-salas do gabinete do superintendente regional do IN CRA viviam lotadas de representantes dos vários grupos locais demandando ações pontuais, fossem em acampamentos ou assentamentos.

0 diferente empenho desses profissionais traz à cena um personagem ainda pouco explorado na literatura sobre movimentos sociais e Estado: o funcionário (Herzefeld, 2005) ou o empregado (Borges, 2006). Na 
maior parte das vezes, subestimado sob o estigma da ação mecânica, esse sujeito pode jogar papel fundamental quando dele dependem, ou quando por ele se fazem os projetos governamentais. Isto porque, numa estrutura de admissão por concurso público, eles têm origem em lugares distintos da sociedade e podem trazer para dentro da estrutura burocrática suas simpatias e antipatias (H erzefeld, 2005: 373) ${ }^{17}$.

Se consideramos o potencial de reflexividade dos líderes dos movimentos dissidentes para lidar com as provas de sua importância social diante do MST e do INCRA, devemos fazer o mesmo agora para o caso dos funcionários. $\mathrm{N}$ a medida em que o M ST e os outros movimentos tomavam as dependências do órgão, o trabalho e a responsabilidade dosfuncionários aumentavam. 0 crescimento da demanda por vistorias, pelos serviços que envolvem 0 atendimento cotidiano e até mesmo a avaliação das terras a serem desapropriadas foi exponencial no período. 0 aumento da carga de trabalho não foi acompanhado por novas contratações de pessoal ou aumentos de salário. Ao perturbarem a vida dos funcionários, as ações dos movimentos passaram também a valorizar o papel social desses sujeitos na estrutura do Estado. Aproveitando a premência das políticas de reforma agrária reclamada pelos movimentos (mesmo que alguns dos funcionários preferissem continuar a ver região dominada por senhores de engenho), a associação dos funcionários passou a organizar greves e protestos pedindo mais recursos e funcionários. 0 próprio MST organizou e continua a organizar manifestações solicitando mais recursos, melhores salários e mais contratações para o INCRA em todo o Brasil ${ }^{18}$.

17 Entre os representantes de movimentos, entrevistados na época da pesquisa, havia uma clara simpatia por certos funcionários de nível intermediário, os chamados quadros técnicos. Por outro lado, todos sabiam da dificuldade em lidar com os procuradores do INCRA, advogados que passam por um concurso concorrido e que em geral têm ligações familiares ou de classe com as elites agrárias da região. Não era difícil também ouvir acusações de corrupção de funcionários por fazendeiros.

$18 \mathrm{Na}$ greve que promoveram no ano de 2007 a principal faixa de uma manifestação em Brasília trazia o revelador slogan "Reforma Agrária: INCRA fortalecido" e outra "200 mil famílias acampadas - reajusta salarial já". Ver http://www.assera.com.br/fotos_incra/07p.jpg. 
Mais uma vez é preciso ressaltar que se trata de situações nas quais o idioma da reforma agrária serve aos movimentose aos funcionários, e que isso não trata de uma relação permanente. Para os fins deste artigo, o mais interessante é que, ao se fundar um movimento e ao se reivindicarem melhores condições de trabalho, as ações coletivas por reforma agrária contribuem para uma transformação na ordem de prioridades do Estado. Transformam-no, não o negam.

\section{O LPM}

Em 2001, foi criado na África do Sul o Landless People's M ovement(LPM) como uma ação de resposta ao fato de os governosque se seguiram ao apartheid não terem realizado o que a Constituição do País previa: a redistribuição de $30 \%$ da terra agriculturável do paísentre a população negra. Segundo a Constituição daquele país, haveria três modos principais de redistribuição de terra: a) a restituição das terras para as famílias que comprovassem terem morado em áreas rurais, antes do ato de 1910 que criou os bantustões ou reservas ou homelands (restitution claimings); b) por projetos de reforma agrária baseados na compra e/ou em expropriação de terras comerciais; c) distribuição de terras para as famílias negras que viviam e trabalhavam em fazendas pertencentes a brancosao longo do apartheid (labour tenants).

Entre 1994 (ano da primeira eleição) e 2005 (ano da primeira conferência nacional sobre o tema da terra), apenas $3 \%$ da terra havia sido distribuída. Como podemos observar, nos três modelos, o foco central é o reconhecimento de direitos (tradicionais, históricos e trabalhistas) das populações negras naquele país. Para isso, desde antes do final do apartheid racial, várias O NG's atuavam na tentativa de defender as populações rurais ${ }^{19}$. Foram estas

19 Entre as principais estavam a Association for Rural Advancement (AFRA) - sediada em KwazuluNatal-; o Surplus People's Project(SPP) em Western Cape; 
mesmas organizações, que, no período que se seguiu ao fim das segregações oficiais, tomaram a iniciativa de comandar os chamados processos de restituição. Para isso, foi criada uma coalizão nacional chamada National Land Comitee (NLC) que reuniu praticamente uma ONG de atuação rural de cada uma das 11 províncias do país na tentativa de unificar as lutas e as reivindicações por direitos das po pulações rurais. Segundo M ngxitama (2006), a NLC teria sido fundada por ativistas com experiência nos modelos de reivindicação urbana, originários do Partido Comunista Sul-Africano (SACP) e da principal central sindical do país, a COSATU.

Tendo trabalhado durante mais de uma década como uma coalizão de O NG's, os dirigentes do NLC, inspirados pelo que haviam visto quando de uma visita ao Brasil durante um dos fóruns sociais, decidiram criar um movimento social aos moldes do MST. Para M ngxitama (op. Cit), cada uma das organizações locais tratou de convocar os grupos com os quais trabalhava para a assembléia nacional de formação do movimento que terminou por escolher uma comissão dirigente provisória. Longe dos mitos de origem de movimentos como o MST, que teriam começado a partir de um evento reivindicatório, o LPM se teria originado, na visão desses autores, de uma decisão burocrática de dirigentes de O N G's e ativistas políticos.

Publicamente, o LPM se manifestou pela primeira vez em 2002, quando da conferência mundial sobre desenvolvimento sustentável (conhecida como Rio + 10), ocorrida em Johannesburg, por meio de uma grande marcha com milhares de pessoas vestindo camisas com os dizeres: LAND, FOOD and JOBS (terra, comida e empregos). A marcha liderada também pelos ativistas da N LC conduziu o LPM para o centro das atenções públicas para além do momento circunscrito da conferência. A mobilização de milhares de pessoas uniformizadas, vindas de vários lugares do país e reclamando por terra contribuiu para que o tema da reforma agrária passasse a ocupar lugar de destaque na mídia que interpelava seguidamente os dirigentes do movimento. A rápida publicização do LPM por meio dosjornais teria feito 0 
movimento tomar dimensões de difícil estimativa. Para quem acompanhava o cotidiano do movimento apenas pelos jornais, parecia que estávamos diante de uma sólida organização com fortes raízes entre as populações rurais do país. Essa impressão ficou ainda mais forte quando, no ano seguinte, em Durban, o LPM voltou a levar milhares de pessoas às ruas com novas camisetas. Naquela ocasião o slogan foi: no land, no vote (sem terra, sem voto). Essa campanha aludia claramente ao fato de que não votariam mais em um governo que, embora se jactasse de um passado de luta contra 0 apartheid, seguia sem acelerar os processos de reforma agrária, apostando em um plano de desenvolvimento nacional conhecido GEAR (Growth, Employment and Redestribution), rechaçado pelo movimento.

Após essas duas grandes marchas, os líderes do LPM passaram a ser convocados para programas de TV e para conferências internacionais. No entanto, de forma distinta do MST, o LPM se consolidou como um movimento de protesto e de denúncia da lentidão nos processos de redistribuição de terras, sem que para isso fossem realizadas ocupações de terra, por exemplo. Desde o princípio, os protestos do movimento tinham um único alvo: a ineficiência do Estado em realizar um programa efetivo de reforma agrária.

Acostumado ao cotidiano do movimento brasileiro, cheguei à África do Sul em setembro de 2005 para acompanhar a visita de dois militantes do MST ao LPM. Se o que eu havia visto no Brasil eram os agitados acampamentos e ocupações de terra que mobilizavam milhares de pessoas em todo o país, na África do Sul conheci um movimento que se estruturava em torno de reuniões. Reuniões com lideranças de províncias, com famílias que estavam sendo ameaçadas de expulsão das fazendas onde moravam por várias gerações, com outras que já haviam sido violentamente expulsas das áreas rurais e hoje viviam na periferia das grandes cidades. Além dos encontros com essas famílias, presenciei vários convites para que as lideranças do LPM se encontrassem com os representados do Estado que os reconhecia como uma força legítima ao os conclamarem como interlocutores nos debates envolvendo os chamados Land Affairs e seus correlatos (que 
iam desde a efetivação da política de restituição de terras, até o controle da epidemia de HIV- AIDS que assola o país e, em especial, as zonas rurais).

Em função das pressões promovidas pelos fundadores do LPM (muitos dos quais ligados ao Partido Comunista Sul-Africano - SAPC) foi realizada em 2005 a primeira conferência nacional sobre os problemas agrários da África do Sul. Naquela ocasião, em um auditório com milhares de pessoas, estavam presentes e convidados pelo Governo, os grandes fazendeiros, os proprietários de agronegócios e também uma dezena de líderes do LPM. Entre todos os grupos que tiveram o direito de subir à tribuna para dar seu depoimento, o único movimento social que teve voz foi o LPM, cujo discurso aparece reproduzido nos anais do encontro ${ }^{20}$.

A pressão do LPM e de outros grupos presentes àquela reunião resultou no reconhecimento, por parte do próprio Presidente da República presente no encontro, de que "somente o Estado seria capaz de garantir o reconhecimento do direito das populações rurais do país". Depois do encontro de 2005, o governo sul-africano decidiu suspender o programa de reforma agrária sugerido pelo Banco M undial (baseado em financiamentos privados para a compra de terras a preços de mercado) e admitiu, pela primeira vez, a possibilidade de o Estado vir a expropriar terras privadas ${ }^{21}$. 0 que aconteceu, pela primeira vez, em 2007.

M esmo agindo de forma completamente distinta do M ST, o LPM tem apontado todas as suas "campanhas" para o governo sul-africano. M esmo sem realizar ocupações de terras - como no Brasil, por exemplo - o LPM deixa claro que suas apostas se voltam para a possibilidade de reestruturar as formas de ação do Estado na áreas rurais ${ }^{22}$. Como as respostas do Governo têm sido débeis, o movimento, assim como aqueles que nele se inspiram,

20 Ver o sítio do Department of Land Affairs. http://land.pwv.gov.za/Land_Summit/.

210 que de fato ocorreu pela primeira vez no ano de 2006 e voltou a se repetir em 2007, em fazendas da provincia de Northern Cape.

22 Há notícias de que, em julho de 2007, o LPM realizou sua primeira ocupação de uma fazenda privada na África do Sul. 
têm variado seu repertório de ações, sempre na busca de canais de interlocução. M esmo estruturados na forma de conflitos os dois movimentos são reconhecidos como legítimos, e isso acontece porque mobilizam objetos que se comunicam com O NG's e Governos, por exemplo.

Longe de negarem a legitimidade do Estado ou mesmo de se oporem a ele, o que se viu na África do Sul nos últimos 5 anos, foi um movimento que lutava o tempo todo para que o Governo reconhecesse e priorizasse as populações rurais como alvo de suas políticas. Ao contrário de uma luta contra o Estado, o que presenciei foi uma luta para que o Governo usasse os instrumentos desse Estado pós-apartheid para garantir a implementação das medidas previstas na Constituição.

\section{Um novo caminho para o paradigma de cidadão não exemplar}

Os temas trazidos à tona nas pesquisas sobre o LPM e o MST se inscrevem no debate mais amplo sobre como interpretar os fenômenos políticos recentes na África e na América Latina. Não são apenas os movimentos sociais que refletem os dilemas da vida contemporânea nesses países: O NG,s, partidos políticos e grupos étnicos envolvem-se obrigatoriamente nesse debate para que sejam aceitos no espaço público.

O clássico de M amdani (1996) sobre a dualidade rural-urbana no continente africano caminha também nessa direção. 0 texto tem por mérito mostrar como os grupos sociais que atualmente dominam as máquinas estatais na forma de governos - sem que sejam necessárias outras qualificações - , são portadores de disputas locais e históricas sobre qual o papel do Estado na região. N aquele contexto, a herança colonial recente teria deixado um legado ambíguo, no qual a feição moderna da vida política e sua organização burocrática estariam limitad os aos aglomerados urbanos (situa- 
ção próxima daquela que vemos no Brasil rural) ${ }^{23}$. As townships e as shantytowns ao redor de Durban, Cape Town e Johhanesburg, não por acaso, teriam sido os palcos das revoltas mais recentes contra o regime do apartheid. Na interpretação do autor, a socialização com vida moderna e suas instituições teriam sido o palco necessário da emergência do Congresso Nacional Africano, do sindicalismo e de seus aliados, que fomentaram uma "cultura" de civil law e, por conseguinte, de cidadania.

Segundo esse mesmo autor, no entanto, a grande parte da população de trabalhadores migrantes e habitantes das reservas rurais etnicizadas ou "bantustões" foi tratada como "objeto" das leis costumeirase das autoridades tradicionais. Tendo seu potencial de revolta coletiva minado, por meio dos clássicos instrumentos da dominação tradicional, as organizações e a população rural teriam sido um dos bastiões do próprio apartheid (a partir da crença na possibilidade da autonomia étnica das áreas rurais levar a independências daqueles territórios) ${ }^{24}$.

Se o LPM não contraria essa hipótese, ao menos a torna mais difícil de ser sustentada. Na medida em que, ao ser aceito nos fóruns do Estado moderno, ela carrega consigo tradições ancestrais e conservadoras e, ao mesmo tempo, exige uma resposta burocrática aos seus reclames por terra, o movimento complica versões mais dualistas. A mobilização do LPM não é a mesma do exemplar uprising de Soweto em 1976 (evento fundante da luta final contra o regime racialista), seu conteúdo é outro. Ao mesmo tempo em que exige a devolução das terras roubadas pelos regimes segregacionistas, o movimento afirma que não quer a terra para se inserir no mercado (fato evidente na rejeição do sistema willing-seller/willing-buyer). $\mathrm{N}$ a maioria dos casos de reivindicações que presenciei, a terra deve permitir,

23 Sobre a relação entre Estado e populações rurais no Brasil em tempos ditos neoliberais, ver Rosa (2007).

24 N tsebeza (2005) revela, por meio de um estudo de caso, as implicações desse abandono político das áreas rurais para o desenvolvimento de uma noção de democracia nessas regiões. 
em primeiro lugar, a continuidade da relação com os ancestrais nela enterrados, o que não permite que se possa aceitar qualquer terra ${ }^{25}$. Em várias situações da pesquisa, pude perceber que a máquina burocrática do Estado moderno sul-africano somente se mobilizava para atender demandas por terras, quando temas como ancestralidade, religião e hierarquias tradicionais estavam em jogo. O u seja, criava-se uma comunidade de sentido, na qual o objeto da argumentação não era a racionalidade instrumental (levada a cabo nos primeiros anos pós-apartheid), e somente assim, certos funcionários (dos vários escalões) se viam desobrigados de seguir as cartilhas dos organismos internacionais como o Banco M undial, por exemplo. Como veremosa seguir, essa espécie de flexibilidade do Estado se corporifica na vida social de seus agentes, cuja maioria, por ser negra, vivenciou casos de expropriação na própria família. Em muitos casos, eles são ao mesmo tempo funcionáriose demandantes do Estado em algum processo de restituição de terras.

\section{Evento exemplar}

No cotidiano da vida política da região, essas situações de difícil definição proliferam. No caso do Land Summit de 2005, por exemplo, eu gostaria de lembrar a entrada da M inistra Thoko Didiza no auditório para fazer abertura do encontro - que definiria o futuro das políticas de reforma agrária na África do Sul. Assim que chega ao microfone, vestida com trajes tradicionais africanos - e não com o terninhos típicos das burocracias impessoais - ela, sem qualquer introdução começa a cantar. Logo que a música começa, todos os membros do LPM que estavam presentes - e que minutos antes manifestavam sua irritação com a inércia da M inistra - começaram também a cantar e dançar fazendo coro para a M inistra. Durante aquele

25 Sobre a relação entre terra e ancestralidade nas lutas contemporâneas na África do Sul, ver o trabalho de Antonádia Borges (2007). 
breve tempo, a Ministra, os membros do LPM e todas as pessoas negras presentes cantaram versos em línguas africanas. Línguas que não eram a do colonizador inglês ou holandês e que criavam uma intimidade entre Estado e movimento - entre funcionários e ativistas - que nenhum esquema a priori poderia compartir. Naquela hora, nem os membros do Banco M undial presentes ou líderes brancos do "agribusiness" local podiam participar. Ao final, puxados pela própria M inistra, todos os presentes gritaram em coro: "que a terra retorne para o povo"; "o poder é do povo", "em frente com a reforma da terra, em frente".

Teríamos aqui elementos de so bra para corroborar todos os estereótipos do discurso populista consagrados pelas ciências sociais so bre a relação Estado/sociedade civil. Porém, nada acrescentaríamos à análise se repetíssemos os velhos conceitos que, como esclarece M aia (2004), não passam de batidas categorias acusatórias. A questão é simples, tais slogans não foram inventados pela $\mathrm{M}$ inistra naquele momento. Todos eles foram forjados durante a luta contra o apartheid, fora, portanto, do Estado e do Governo, e em um tempo, todos os que ali cantavam tinham como bandeira a recuperação de seu lugar social na África do Sul.

Retomando novamente a noção de prova de Boltanski (2000), vemos que os objetos e as provas não são os mesmos do Brasil. 0 que permite ao LPM manter-se dignamente em relação com os funcionários do Estado é seu passado comum, um passado cujo ícone é a relação com a terra, que se exprime no grito "devolvam nossa terra". Mesmo que a lógica do ofício indique que a reforma agrária seja apenas um política pública, o que podemos observar na África do Sul é que ela tem sido a forma da política por excelência. U ma política que comunica sujeitos que vivem nas cidades e nas zonas rurais com seus governantes e representantes, de forma visceral, e que vai além dos esquemas duais tradicionais que se valem de idéias como cooptação ou autonomia, para definir ações coletivas. 
Tais considerações não visam afirmar que o LPM é um movimento de unanimidade ou que ele tenha encaminhado suas ações sempre com sucesso (o mesmo vale para o MST). Afinal, essa relação entre os movimentos que lutam por terra e o Estado não pode ser reduzida apenas a essa comunicação sem ruídos por meio de um passado recente. $N$ ão podemos esquecer que os que falaram Zulu, Xhosa e outras línguas africanas nas canções e slogans repetidos no Land Summit também falam com desenvoltura o inglês e 0 "africaans". O u seja, se o passado compele os agentes do Estado a compreenderem a situação do movimento, o presente os coloca também em uma relação obrigatória com os grandes organismos internacionais e com a própria elite econômica branca. Como se instituiu dizer desde o final do apartheid, a África do Sul vive um processo de reconciliação, no qual uma parte importante do passado dever ser esquecida, para que se garanta o futuro. Sendo assim, nem sempre as lembranças que o LPM traz a público são palatáveis aos novos tempos. Daí as dezenas de processos judiciais levados a cabo pelo Estado contra as lideranças do movimento nos últimos anos.

M esmo sendo estruturadas a partir de objetos e ordem de legitimidades distintas, as situações dos sem-terras no Brasil e na África do Sul são comparáveis porque ambasapontam para a centralidade do reconhecimento do Estado. Reconhecimento este que não se dá de cima para baixo ou por mero zelo burocrático, ele somente ocorre porque, em situações distintas, os próprios sem-terras estiveram na gênese contemporânea dessas instituições. Seja lutando por funcionários para o Incra ou por um governo da maioria negra.

\section{Notas finais sobre as implicações sociológicas desses dois fenômenos}

Países que não são exemplo para nenhuma teoria sociológica contemporânea (ao contrário são os lugares que não cabem nos modelos) e um tipo 
de vida (rural) que é visto como uma etapa desvalorizada e em extinção da vida moderna. Brasil e África do Sul, MST e LPM, desafiam as sócio-lógicas atuais quando vistos como lugares de ações coletivas de grande magnitude.

Ao serem vistos de uma forma comparativa horizontal e não vertical (como fazemosao nos pensarmosem relação à Europa), esses dois casos apontam para processos sociais semelhantes: a construção das lutas coletivas agráriascomo caminhos para a reconstrução do Estado com característicassingulares. Características modernas, pois incorporam estruturas burocráticas que são capazes de reconhecer indivíduos e lutas coletivas de forma diferenciada.

N os casos que venho pesquisando, fica claro o papel central do Estado nas lutas por terra no Brasil e na África do Sul. Em ambos, por meio de modos distintos de ação coletiva, os movimentos têm buscado e, em certa medida conseguido, o reconhecimento legítimo de situações sociais antes julgadas impensáveis. Graças a movimentos como esses, no Brasil e na África do Sul, catego rias como "sem-terras", "farm- $d$ wellers" ou "restitution claims", tornaram-se moedas correntes no vocabulário político. A eficácia social desses mesmos termos produziu-se na medida em que, nos dois casos estudados, foram sendo incorporadas às políticas públicas dos Estados. Essa incorporação somente ocorre porque o Estado não pode ser visto como um deusex-machina em relação às ações sociais, não podendo ser visto nem como o inimigo da coletividade nem como seu capturador incondicional.

Em torno das respostas, positivas e negativas do Estado, os dois movimentos sociais têm reinventado as formas de luta sociais nos distintos países. Ao reconhecer esses movimentos como portadores de reivindicações legítimas, os agentes do Estado reconhecem (e não apenas a eles atribuem) que os indivíduos que neles se engajam ocupam um lugar especial na coletividade. Mesmo que esse lugar - por vezes uma ligação ancestral - não esteja previsto nas formas de reconhecimento moderno, descritas pelas teorias exemplares. 0 cupando um lugar que é reconhecido como legítimo, 
esses indivíduos podem, sim, recriar as formas de ação coletivas e, por conseguinte, as formas de organizar as coletividades sociais.

Assim, levando em conta o itinerário epistemológico oferecido pelas lutas desses dois movimentos, deixamos de ter apenas uma teoria dos movimentos sociais e passamos a ver o estudo desses movimentos como fundamental para a compreensão das formas contemporâneas de sociabilidade política. Esta compreensão incita uma teoria mais geral que incorpore a experiência social africana e brasileira, não como defeito, periferia ou dependente. Nessa teoria historicamente localizada, a experiência heurística de relação entre as lutas coletivas e as transformações do Estado exigem uma Sociologia que se reinventa não mais a partir da imposição de modelos, mas pela incorporação processual da vida social cotidiana.

\section{State and collective actions in South Africa and Brazil: for a contemporary sociology of non-model countries}

\section{Abstract}

This article analyses the actions of the Landless Workers' M ovement (MST Movimento dos Trabalhadores Rurais Sem Terra) in Brazil, and the Landless People's M ovement in South Africa, in order to examine the form that the State assumes in these two social contexts. Its main objective is to show that in these countries, here defined as non-model, it is necessary to develop a complex theory to break away from the sociological dichotomy state/civil society. To break with the traditional analytical schemes, focused on the European case, it is necessary to embrace new and less biased ways of understanding the political forms of social belonging in the southern countries.

Keywords: Collective actions. State. Land reform. South Africa. MST. 


\section{Referências}

BO RGES, Antonádia. M ats, blankets, songs and flags: ethnography of the politics of funerals in contemporary South África. Texto apresentado no III Ethnografeast, CEAS, Lisboa, 2007. Disponível em

http://ceas.iscte.pt/ethnografeast/papers/antonadia_borges.pdf, acessado em 15 de maio de 2007.

BO RGES, Antonádia. 0 Emprego na Política e suas implicações teóricas para uma antropologia da política. Anuário Antropológico 2005, Rio de Janeiro, p. p. 91125, 2006.

BO LTANSKI, Luc e THEVEN OT, Laurent. De la justification. Paris: Galimard, 1991.

BO LTAN SKI, Luc. El amor y la justicia como competências. BuenosAires: Amorrotu, 2000.

HERZEFELD, Michael., Political O ptics and the 0 cclusion of Intimate Knowledge. American Anthropologist, Vol. 107, n. 3, pp. 369-376, 2005.

HO N NETH, Axel. A luta por reconhecimento. São Paulo: Editora 34, 2003.

M AIA, João M. A História de um Conceito: 0 Populismo no Brasil. 2001. Dissertação (M estrado em Sociologia), IU PERJ, Rio de Janeiro.

MAMDANI, Mahmood. Citizen and subject. Princeton Unversity Press, 1996.

LI, Tania., Beyond "the State" and Failed Schemes. American Anthropologist, Vol. 107, Issue 3, pp. 383-394, 2005.

MARTINS, Jose de S. Reforma agrária: o impossível diálogo. São Paulo: Edusp, 2000.

M N GXITAM A, Andile., The Taming of Land Resistance: Lessons from the National Land Committee. Journal of Asian and African Studies. N. 41, pp. 39-69, 2006.

NAVARRO, Z. Mobilização sem emancipação: as lutas sociais dos sem-terra no Brasil. In: Santos, B. de S. (org.), Produzir para viver: os caminhos da produção não capitalista. Rio de Janeiro: Civilização Brasileira, 2002, pp. 189-232.

NTSEBEZA, Lungisile. Democracy Compromised: chiefs and the politics of land in South África. Brill, Leiden, 2005.

PALM EIRA, Moacir., Casa e trabalho: notas as relações sociais na plantation tradicional. Actes du XLII Congrès des Américanistes. Paris: Société des Américanistes/M usée de l'Homme, 1978, pp. 305-15.

ROSA, Marcelo. 0 engenho dos movimentos: reforma agrária e significação social na zona canavieira de Pernambuco. 2004. Tese (D outorado em Sociologia), luperj, Rio de Janeiro. 
ROSA, M arcelo. Uma região em M ovimento: as lutas por terra e a transformação das estruturas de poder e significação social na mata Pernambucana. Revista Brasileira de Estudos U rbanos e Regionais (AN PU R), v. 8, p. 41-58, 2006.

ROSA, Marcelo. Oligarquias agrárias, o Estado e o espírito do neoliberalismo no Brasil. In: Alejandro Grimson. (O rg.). Cultura y neoliberalismo. Buenos Aires: Clacso, 2007, p. 111-125.

SAYAD, Abdemalek. A imigração. São Paulo: Edusp,1998.

SIGAUD, Lygia. A forma acampamento: notas a partir da versão pernambucana. Novos Estudos Cebrap, n. 58, 2000, p. 73-92. 